\title{
The Many Roles of Empathy
}

Empathy has become a hot topic in philosophy, but I think empathy is much more philosophically important than its recent advocates, myself included, have realized. During the last few decades many philosophersthough perhaps not a majority-have come to think that empathy has an important role in moral motivation, that compassion, for example, is often or always psychologically powered by empathy with someone's miserable condition. Chapter 2 above argued for this specific point and took the more general view that sentimental virtues like compassion and benevolence are best understood in relation to empathy. Now this last is a claim of normative ethics, but some philosophers think that empathy plays a role in our concepts and judgments of right and wrong, and in that case empathy is important not just to ethics but to metaethics as well. ${ }^{1}$ It is also widely recognized that empathy helps to put us cognitively in touch with what others are feeling and does so much more directly than by any form of argument or inference. This gives empathy an epistemological role outside of ethics, but I want to show you that that role has been totally underestimated. I want to show you how empathy plays a role in our general knowledge of the world outside of us and also hope to show you that empathy plays a cognitive or epistemic role in moral knowledge than has

\footnotetext{
${ }^{1}$ This is Hume's view in the Treatise of Human Nature, and it can also be found in my recent book Moral Sentimentalism (which I shall be speaking further about in what follows).
} 
ever been appreciated. Empathy turns out to be the moral sense that Francis Hutcheson spoke of but never really nailed down for philosophers; and Hume, for all his deep thinking about empathy (he called it "sympathy"), never saw that it could be the moral sense that his mentor Hutcheson had been looking for and/or talking about. I shall explain why in what follows, but that is not the end of empathy's unexamined, unexplored, philosophically significant roles. Empathy is essential to speech acts in a way that speech act theorists have totally ignored. I shall here try to make good on all these points.

\section{1}

First, let me talk about a very specific epistemic role for/of empathy that the recent literature of epistemology has ignored. Epistemologists and, especially, virtue epistemologists have spoken of open-mindedness as an important epistemic virtue, an important element in epistemic rationality. And some mention has been made of the virtue of receptivity in this connection. An open-minded person has to be at least somewhat receptive to new ideas and to views that at least initially they disagree with. But what no one has pointed out is that this kind of epistemic receptivity (one can also be receptive to people's suggestions about what one should do) depends on empathy, involves being willing and able to see things from the point of view of another person or persons who disagree with one. However, this point, once it is made, seems fairly obvious (and is to some extent anticipated by what was said about open-mindedness in Chap. 4). Let me now turn to some deeper aspects of empathy's significance for the theory of knowledge.

The kind of empathy that takes in the feelings, attitudes, and so on, of others (what is sometimes called associative or receptive empathy) clearly allows us to pick up on, to recognize, what others are feeling, and to do so without any belabored form of inductive or abductive inference. (I shall for the moment play down the distinction between being aware of how someone is feeling and being aware that they are feeling a certain way.) So empathy is a direct, non-inferential way of knowing about other minds, and the literature on empathy frequently emphasizes that fact. (Mirror neurons are obviously relevant here.) But I think empathy has a far greater cognitive or epistemic significance than the one we have just mentioned. To be sure, it helps us recognize what others are thinking or feeling, but, much more importantly or at least much more broadly, it helps us learn 
facts about the world that as facts or realities lie beyond and/or are independent of the other minds (or rather xins) we empathize with. And this fact about the epistemic usefulness and value of empathy hasn't, I think, been recognized in the literature, both philosophical and otherwise, on empathy. Let me explain.

If your parents fear bears, you, as a child, can empathically pick up on or (osmotically) take in that fear and learn thereby how your parents feel about bears. But their attitude about bears is presumably based on what they have learned about the world (perhaps it was picked up from their parents, but this sort of process has to originate, I think, in perceptually learning about the world in ways that don't involve empathy). And by empathically taking in their attitude toward bears, the child can acquire knowledge of how the world beyond his parents actually is, can learn, and/or have reason to believe that bears are dangerous or to be feared. Similarly, if the child feels their parents' trusting attitude toward Aunt Tilly, they can learn what their parents have already learned earlier on: that Aunt Tilly is someone they can rely on. And so on and so forth for a large variety of other cognitive cases. Therefore, empathy with others is also a way of learning about the world beyond those others that the others have, let us assume, learned about through typically non-empathic modes of learning like perception, memory, induction, abduction. This kind of empathic learning may be parasitic on the latter types, but one person's parasitism is another's second-order status. Just as memory beliefs can be second order in relation to perceptual beliefs because they involve memories or a memory of how things perceptually seemed to us in the past, so too can empathic learning about the world be second order or higher order in the way it depends on empathy with other people and on what those one is empathizing with have learned via or believe as a result of perception or memory or abduction, and so on (or even empathy), in the past. (Also most empathy involves us in actually seeing someone, but in order to simplify the discussion, I shall ignore this fact in what follows.) Somehow the fact that we can learn about the world through empathizing with other people's attitudes or views about the world has escaped the attention of epistemologists.

But one shouldn't be too extreme about all this. Just as memory and perception can sometimes serve us badly, empathy can serve us badly too. If one's parents are bigots who think all Jews are out to do people dirt (or worse), then one is going to pick up an epistemic attitude that is far from justified (paranoia epistemically distorts someone's reality) and that isn't 
likely to serve one well in one's life. So empathy isn't fully reliable, perhaps isn't as reliable as memory and perception typically are. And that very fact may help account for the neglect of empathy in discussions of the modes and bases of justified human knowledge and cognition. However, the fact that perceptual beliefs are sometimes mistaken doesn't undercut the idea that most perceptual beliefs are justified, and by the same token the fact that empathy sometimes takes in beliefs that are based in paranoia and totally unjustified doesn't mean that in most cases what we empathically take in from others about the world isn't justified and doesn't count as knowledge.

But empathy not only plays a greater role than anyone has imagined in the acquisition of empirical knowledge or justified beliefs about the world, but also undergirds certain forms of moral knowledge in ways that have not been recognized. Almost everyone knows that empathy can (often) help us identify those who need our help more immediately or quickly than other modes of cognition, and this clearly makes empathy epistemically relevant to the moral life. But empathy also can help us recognize the virtue or vice of those we come into contact with (or read about). In fact, I think it is our primary mode of access to (the) moral attributes (of individuals or groups).

\section{2}

In the eighteenth century Francis Hutcheson argued that human beings have a moral sense that enables them in something like a perceptual way to detect the moral goodness/virtue or moral badness/vice of other human individuals. But to subsequent generations of philosophers the idea of a moral sense has seemed like nothing but a metaphor, and Hutcheson's most famous student or mentee, David Hume, was unwilling to countenance the idea of a literal moral sense. In fact, many of the ethicstheoretical tasks that Hutcheson attempted to accomplish using the idea of a moral sense were addressed by Hume using the concept of empathy. (He used the word "sympathy" in describing the tasks because the word "empathy" hadn't been invented yet, but it is pretty clear to most scholars that Hume was referring to empathy on many of the occasions on which he spoke of "sympathy.") But I am not going to review all the things or even the most important things Hume says about empathy/sympathy because, as far as I know, Hume never said that the operating of empathy gives us a way of perceiving and knowing the moral goodness or badness of individuals or groups of individuals. 
However, in the area of moral philosophy I am in large part a follower of Hume, a sentimentalist in regard both to normative morality and to metaethics or moral semantics. And the account of moral semantics that I have offered more fully in my Moral Sentimentalism (OUP, 2010) allows us (in a way that that book doesn't take full advantage of) to see empathy as providing us with a way to perceive the moral virtue or vice of people around us. In order to show all this, I am going to have to describe, as briefly as I can, what that book says about moral semantics; and the justification for doing that will lie, as I have suggested, in the way such a semantics, a sentimentalist semantics, allows for the perception and knowledge of people's moral traits via empathy.

We are sometimes warmed by the warmth another person demonstrates or exemplifies toward some third party, for example, toward a friend. And in Moral Sentimentalism (henceforth MS) I argued that when we are thus warmed by another, we are, in a most basic way, morally approving of them or of what they are trying to do. But by the same token we can be chilled by the cold-heartedness someone displays in their attitude or actions toward some third party, and MS argued that this constitutes a basic kind of disapproval of that cold-hearted person. (The phrase "the chill of disapproval" is some indication that we think of disapproval as cold or chilly in this way.) MS and some later work of mine replying to critics of and commentators on that book offered numerous arguments for conceiving moral approval and disapproval in this specific sentimentalist way, and it is perhaps already clear to you that when I speak of being warmed by warmth or chilled by cold-heartedness (or heartlessness), I am speaking of an empathic process. Just as we can empathically register the pain of another in the way we describe when we say "I feel your pain," we can register the moral goodness or badness of someone's actions or attitude by empathically taking in the warmth or coldness that person is displaying in their actions. Or, at least, we can do this if moral goodness/vice consists of being a warm-hearted or caring person and moral badness/vice consists in lacking warm-hearted concern for others and/or being cold-hearted toward them. (Both indifference to the welfare of others and actual malignity toward them constitute ways of being cold-hearted toward other people or animals-more on this in Chap. 6.)

Now ethical rationalists will say that moral goodness requires more than warm-hearted concern for others, that it requires, for example, that one honor certain deontological constraints on action even when the violation of those constraints might actually be helpful to other people (or more helpful 
than it would be to honor the constraints). If I am a surgeon and can save the lives of four car accident victims by secretly cutting up some stranger, then it might seem that the saving of a greater number of lives would be dictated by a general warm-heartedness toward humanity, and this would then show that warm-heartedness isn't sufficient for moral goodness either in given instances or more generally. If we assume, as I assume, that it would be wrong to cut up one innocent healthy person in order to save or preserve a greater number of lives, then moral goodness seems to involve more than, or something different from, overall warm-heartedness.

But in MS I argued that warm-heartedness toward others requires and is based in empathy toward others and argued further that empathy registers and is sensitive to the causal distinction between doing and allowing in a way analogous to the way it is also sensitive to the distinction between (potential) suffering we are immediately aware of and (potential) suffering we only indirectly know about. Other things being equal, it is morally worse to ignore the distress or suffering of someone whose distress or suffering one is immediately and perceptually aware of than to ignore distress or suffering one only knows about, and, MS argued, this reflects the fact that empathy is more sensitive to perceived distress than to known-about distress. MS also sought to show that empathy tends to be more sensitive to the causing of harm than to the allowing of harm and that this conclusion supports deontology. But of course such an argument assumes, what MS sought to show, that empathy enters into our moral concepts of right and wrong, virtue and vice. And let me say just a bit now about how that is or was supposed to work.

I above described states of empathically registered warmth as states of moral approval and states of empathically registered chill or coldness as states of moral disapproval. But MS went on from those assumptions to show how moral goodness and badness, virtue and vice, can be understood on that basis and making use of the phenomenon and of the concept of empathy. I argued in a way that borrowed to some extent from Saul Kripke's views in Naming and Necessity that the empathic warmth we feel in viewing or learning about the warm caringness of others (a caringness that itself reflects the capacity for and reality of empathy on the part of those others) fixes the reference of moral goodness/virtue for us. ${ }^{2}$ Moral

${ }^{2}$ Naming and Necessity, Cambridge: Harvard University Press, 1980. Incidentally, the account of moral meaning that MS offers is naturalistic (and a form of realism) inasmuch as it (for example) identifies moral goodness very roughly with empathic caringness. But that 
virtue, in other words, is that property of other individuals or their attitudes or actions that is (in the absence of perceptual/cognitive error) empathically registered in us as a feeling of being warmed. And the only property of others that can (veridically) be empathically registered as warmth is warm caringness on their part. Similar arguments then also apply to moral vice or badness, with our chill reactions paradigmatically fixing the reference, for us, of the concept of moral badness. Now on Kripke's view the reference fixing is not in any way analytic or definitional with respect to the natural kind terms ("tiger," "red," and "gold," for example) that he was interested in helping us understand. It is not analytic or even metaphysically necessary that the red experiences that fix the reference of "(objectively) red" are caused by red objects. In another world, Kripke argues, green objects might cause the experiences we now typically have when we see red objects in good light. However, MS argued for a partial disanalogy between what Kripke said about natural kind terms and what it wanted to say about moral vocabulary. If moral goodness is whatever is (in veridical circumstances) the cause of our being warmed by another's attitude or actions, if it is whatever is the cause of moral approval

doesn't mean that it can't account for the normativity (motivating and reason-giving force) of moral claims. Sharon Street (in "Reply to Copp: Naturalism, Normativity, and the Varieties of Realism Worth Worrying About," Philosophical Issues 18, 2008, pp. 207-228) has argued that the naturalism David Copp has defended cannot account for moral normativity, but the naturalistic account of moral meaning I have offered does allow for this because empathy neatly straddles the supposed divide between fact and motive. In empathizing with the distress of another person, we both cognitively register that mental state and identify with it in a way that constitutes motivation to help them. (This follows from what I said in Chap. 2 about the necessary connection between associative empathy and sympathy/altruism.) Similarly, it can be shown that emotion-based prudential reasons can empathically transfer to observers and give them reason to help someone who needs their help. (I argue for this at length in my The Philosophy of Yin and Yang.) So metaethical naturalism of a sentimentalist kind can account for the objectivity of moral judgments at the same time that it helps explain their normative force. And this fact also helps the sentimentalist answer the challenge to realist theories of value mounted by Street in her earlier "A Darwinian Dilemma for Realist Theories of Value," Philosophical Review 115, 2006, pp. 109-166. Even if evolution has shaped our moral capacities and moral language, what we say with that language may be guaranteed as true if naturalism about moral meaning holds. This leaves open the evolutionary possibility of humans or other intelligent creatures with evaluative notions different from those we actually have. But we already know that there are tribes and cultures that seem to lack our moral notions, and should we be any more uncomfortable with the possibility of creatures evolving with evaluative notions very different from our own? I am not sure that we should be, but this is an issue best left for discussion elsewhere. 
understood as the state or process of being empathically warmed by another's warmth, then it follows that moral goodness consists in a kind of warmth or warm-heartedness toward others, and of course no one can count as warm-hearted unless they have certain dispositions to help others or not harm them. So it is at the very least a priori and necessary that moral goodness consists of being generally warm-hearted, or, as we may prefer to say, caring, toward other people (or sentient beings generally). Moral vice or viciousness then consists in the opposite or contrary trait or disposition of cold-heartedness toward others.

All of this, of course, assumes that we can properly and automatically describe a caring or sympathetic individual as warm-hearted, and a number of other assumptions also have to be brought into the mix for the above picture of moral goodness and vice to emerge as a plausible account, given in sentimentalist terms, of moral properties. But I don't propose to give any more of the argument here. ${ }^{3}$ Rather, I would like to show, on the basis of

\footnotetext{
${ }^{3}$ Or let me put just a few more points in footnote here. Some writers on empathy (e.g. Jesse Prinz and Paul Bloom) question its moral value on the grounds that empathy can lead someone morally astray. That is absolutely correct, but there is a difference between ordinary, limited, blinkered empathy and the larger fully empathic caringness that I think is the touchstone of our moral concepts. What is morally good (and warms us when we are properly informed) is not what shows some degree of empathy and caringness, but what represents a fully empathic and caring response to a situation of moral choice. If I have empathy for family members but not for others, then I am not a caring person, am not a fully caring individual (my overall empathic dispositions will be chilling to others who find out about them). And I argued in Moral Sentimentalism that we need moral education, the broadening of empathic horizons, if we are to be fully moral individuals. That book dealt with all kinds of cases where this stricter criterion gives us the right moral answers even if a blunt appeal to empathy does not. And I should finally mention that in other work (e.g., Education and Human Values, NY: Routledge, 2012) I have attempted to show that Prinz and Bloom's common assumption that moral motivation can be based in reason is very dubious. There is very little evidence that sheer reason can motivate moral action in the way that empathy and caring can: the example of psychopaths can help one make the sentimentalist case here. It is also worth pointing out in this connection that when a mother takes her frightened protesting sick child to the doctor despite her empathy for what the child is feeling, we don't have a case where empathy is trumped by non-empathic rationality. Any normal mother will be vividly aware of what will happen to her child if they aren't taken to the doctor, and this represents an enlarged form of empathic sensitivity that can psychologically outweigh the narrower and more immediate empathic distress she may feel at seeing her child's fear. A person is lacking in empathy and concern for others if their empathy and caring can't extend beyond the immediate and present, and any mother who allowed her empathic distress to prevent her from taking her very sick child to the doctor would actually show a lack of empathy for her child. (We may also want to say there is something rationally defective about her.)
} 
what I have just been saying (and what MS has already said), how empathy enables us to perceive the goodness or badness of other people or their actions or attitudes. (In what follows I am very much indebted to discussion with Nancy Snow.) The fact that we empathically register the warmth or cold-heartedness of others in and through feelings of warmth or chill in ourselves can be seen, as I have just argued, as the basis of our concepts of moral goodness and moral badness (wrongness enters the picture via badness). But given those concepts and how they apply (namely, that goodness is a kind of caringness, etc.), when we empathically register the moral goodness of someone's attitude, actions, or overall moral character, we are in effect perceiving that goodness. And that, arguably, allows us to say that empathy is the special moral sense that Hutcheson was talking about or reaching toward. (Note that the frequently made objection that, unlike the familiar five senses, there is no physical basis for a moral sense is undercut if empathy as the moral sense is underlain by certain functionings of mirror neurons.) More specifically, empathy is sensitive to degrees of caringness or its absence, and that sensitivity is realized in states of warmth or chill that vary with the caringness of people we become aware of. So there seems to be every reason to say that when we are empathically warmed by another person's warmth or warm-heartedness we are perceiving that warm-heartedness. And since on the theory being developed warm-heartedness in various degrees (and on a priori grounds) just is moral goodness in various degrees, our perception of warm-heartedness just is a perception of (greater or lesser) moral goodness (in acts, attitudes or overall character).$^{4}$

\footnotetext{
${ }^{4}$ Degrees of warm-heartedness or warmth aren't measured or registered via some simple quantitative metric that is built into empathy; rather our sense of what is warm or warmer is the complex and vectorized product of the way we empathically register or perceive various interacting empathy-inducing and empathy-displaying factors. Empathy is more aroused by perceptual acquaintance (as opposed to knowledge about), by direct causal connection to some harm or good, by contemporaneity (rather than probable or even certain predictability for the future), and by lines of family consanguinity and connections of personal intimacy. But we are also capable of being empathically sensitive to what is distant or future, and sheer numbers also affect our empathic reactions. In fact, fully-developed empathy is subtle. We can make as many distinctions with empathy as we are supposed to be able to make via practical reason operating in the moral sphere, and once we vectorize relevant empathic factors as instantiated in a given situation (is the person being sensitive to their degree of causal involvement with the goods or evils that are at stake? is the person being sensitive to what they perceive and don't just know about?), we can have a subliminally empathic and then a more self-conscious sense of how (empathically) warm and caring someone's behavior or
} 
Buying into the sentimentalist moral semantics (with accompanying normative views) that I sketched above and elaborated at great length in MS allows one, therefore, to see another epistemic use or usefulness in our capacity for empathy. We can not only empathically register, and in that measure perceive, what others are feeling or thinking; we can not only, through such registration, immediately learn things about the world that others have had to learn through extended and sometimes painful experience but also perceive the moral virtue and vice of others or their actions via empathy. And the analogy with the five senses works all the better if one remembers that just as those five senses work directly and without inferences, empathy often puts us in touch with what people believe and know about the world without resting on any sort of inference.

In addition, and again as with ordinary visual or auditory perception, the perception of virtue and vice needn't amount to any knowledge-that. A child can perceive or see a piano without knowing that it is a piano and without knowing what pianos are. And similarly I believe that a person, say, a child, can be warmed or chilled by the attitude of another human being in a way that constitutes perceiving virtue or vice, without yet having the concept of moral goodness, and (thus) without being able to say or think that the person in question is morally good or bad. In this respect too, then, the analogy between what empathic sensitivity gives us and what ordinary perceptual sensitivity gives us makes the idea of empathy as a mode of moral perception and even of moral knowledge (though the knowledge will be knowledge by acquaintance, not by description) seem all the more plausible and attractive. ${ }^{5}$

attitude in that situation is. (All this presupposes that facts aren't being hidden or obscured in the given situation and that we are talking about the empathic perceptions of a morally sensitive individual.)

${ }^{5}$ The child who doesn't yet grasp the concept of moral goodness may empathically perceive or feel someone's goodness, but once they have that concept they will be able, presumably, to empathically perceive that a given person is morally good. That is analogous to what we find with ordinary sense perception, where we can perceive a material object without knowing its nature but can also perceive that some material object has a given property. This corresponds to the distinction between extensional and intensional perceptual contexts, a distinction that is as relevant to empathic moral perception as it is to ordinary sensory perception. The same sort of distinction also applies to empathic perception of something one's parents have learned about the world. A child can empathically sense or perceive the dangerousness of bears through empathy with their parents fears and even while lacking the concept of danger. But later on one's empathy with one's parents or others can allow one to empathically perceive that bears are dangerous. Incidentally, I have been somewhat evasive about 
I am far from done. Empathy also has a (variegated) major or even universal role to play in speech act theory that has long gone unrecognized or unappreciated. That role relates both to what empathy tells us about the people we empathize with and to what it tells us about the things those people know or justifiably believe about the world, but it involves those just-described facets of empathy in a quite distinctive way. However, I want to introduce these further uses or roles of empathy by focusing first on the way it tells us about other people.

When I empathically register another's pain or joy, I have a direct way of knowing about their state of mind. Even if people are sometimes faking their emotions and can be very good actors, the fact we can be fooled in such circumstances doesn't show we aren't directly justified in believing they are in the psychological state we think they are in and likewise doesn't show we can't in other circumstances actually know that they are feeling one or another attitude (and remember on the view defended in Chap. 2, belief is a kind of favoring attitude). After all, the epistemology of perception offers similar problematic cases, and we philosophers want to say that perception can, nonetheless, often be a source of knowledge and epistemic rational justification.

However, when we think of the ways we can empathically pick up the feelings of others, we typically aren't thinking of ways in which what they say or assert helps us empathize with their mental states. We are thinking of cases where their non-verbal behavior leads us to empathically register what they are feeling. But what people say can also causally bring about the empathic registration of what others are thinking, wanting, or feeling, and ordinary speech acts constitute a prime example of how this can happen. Speech act theory has ignored the ways in which this can happen, but when we closely examine some of those ways, I think we will be able to see that various standard forms of speech act work to a substantial extent via empathic processes.

whether a child who receptively picks up beliefs or attitudes from her parents is epistemically justified in having those beliefs or attitudes even when the parents aren't. But I would like to think (though this needs further discussion) that the receptivity involved at the child's end gives them a justification even if the parents lack such justification. One could say that receptivity operates as an epistemic virtue only when it operates on what is itself justified via receptivity and/or other factors, but it is at least simpler to hold that when a child is receptive to their parents' (unbeknownst to themselves, unjustified) beliefs, they at least are justified as a result of the receptivity they are manifesting (and their parents presumably are not). I am inclined to go in this direction, but if you give me a good argument against this way of seeing things, I might be persuaded to think otherwise. 
Now I am not going to expound speech act theory or theories in any detail. Rather, I propose to describe some characteristic claims of such theory in regard to certain particular speech acts, recognizing too that the literature on speech acts has spawned a great number and variety of putative or generally acknowledged counterexamples to (some of) the particular formulations of speech act theory that have been offered. But the counterexamples don't point to any need to bring empathy into the discussion; they have led speech act theorists to more and more complex or ingenious formulations of the conditions of particular speech acts without suggesting to anyone so far that empathy could be useful to their whole enterprise. My point is that even if the counterexamples could be got rid of via sufficiently clever or complex reformulations of the conditions offered concerning various speech acts, there would be a problem of completeness with the resultant theory because it would still be focusing too narrowly on the factors at play when someone performs the speech act of assertion or asking a question, and so on. Moreover, the factors I shall point out aren't like physical factors that speech acts theory doesn't mention but that have to be operating in our physical universe in order for speech acts to occur and be successfully brought off. The physical factors are at the wrong theoretical level to be relevant to what the speech acts theorist wants to say: the physics of sound and moving bodies (vocal cords and lips) doesn't seem relevant to speech acts as speech acts. But I think the reader will see that the empathic factors and processes I am going to mention are relevant to speech acts as speech acts and to the success or felicity of speech acts as speech acts.

Let me begin by mentioning and discussing a well-known account of the meaning or force of speech acts, that of $\mathrm{H}$. P. Grice in various articles and books. ${ }^{6}$ Again, as I just indicated, what Grice said was subject to

\footnotetext{
${ }^{6}$ See, inter alia, Grice's “Meaning," Philosophical Review 66, 1957, pp. 377-388; and his “Utterer's Meaning and Intentions," Philosophical Review 78, 1969, pp. 147-177. Grice elsewhere introduces his highly influential notions of conversational and conventional implicatures/implications. These are important factors in speech acts, and they engage empathy and even emotion in ways there is no time to fully enter into here. Let me just mention, however, my own attempt to understand the emotive meaning of value judgments in terms of Gricean implicatures. In Chap. 5 of Moral Sentimentalism (OUP, 2010) and in some much earlier work as well, I argue that the emotive meaning of a statement like "Joan was a good Catholic" is its cancelable Gricean implication that the utterer has a good opinion of Joan. In that case, when that implication hasn't been canceled, the statement expresses an emotion toward Joan that the hearer can empathize with. This idea is present in the work of Charles Stevenson cited below-but Stevenson's view that value judgments are primarily
} 
counterexamples, but can nonetheless illustrate the need to bring in factors of empathy that aren't even so much as alluded to in his account of various speech acts. So, roughly, Grice holds that to assert to someone that something is the case (or, in speaking to someone, to mean that something is the case) is to signify or indicate one's intention that they should believe what one is asserting because of their recognition of that very intention (on one's part). Similarly, to ask someone a question is to indicate that one intends that they should give one the or an answer to that question on the basis of their recognition of that very intention.

But, one may ask, how does the recognition of the speaker's (or writer's) intention actually cause someone in the one case to actually believe what the person has asserted and in the other case to try to answer that question? Well, in the former case this may depend on what the hearer knows or believes about the speaker or, possibly, on how the hearer is related to the speaker. If the hearer believes that the speaker is honest and also believes that they are a reliable judge of truth and falsehood in various areas of their (the speaker's) life, they may have an inductive or even abductive argument in favor of believing what the speaker has asserted. But according to some theories (e.g., Thomas Reid's), one may have reason to believe what speakers or writers assert even in in the absence of any inductive/abductive argument for the reliability or honesty of those particular speakers/writers. ${ }^{7}$

emotive is very much called into question when one thinks their emotive meaning is cancelable and thereby allows that value judgments can in the strictest sense be true or false.

${ }^{7}$ Thomas Reid, An Inquiry into the Human Mind, Chicago: University of Chicago Press, 1970, esp. pp. 234ff. I am assuming here that when the child takes in the parental fear of bears, they don't do it via an argument or inference from the reliability of their parents. But Reid argues that God has implanted a tendency to speak truth and a tendency to believe what one is told in all human beings (even and especially children), and he therefore holds that "testimony" has an intrinsic authority among us humans irrespective of any argument based on the belief that a given person is generally reliable in what they say. I shall say more about Reid's views about the way assertions work below, but he clearly thinks belief in what one is told occurs in a direct manner, and so his take on assertion treats it as working in something like the direct and non-inferential way that I shall argue empathy works in the context of assertions. In addition, although reliability is a familiar abductive/inductive matter, the authority of testimony is a less familiar issue, and one can wonder whether there really is such a thing. (Hume's discussion of miracles makes it pretty clear that he didn't believe testimony had any authority beyond its reliability, and Reid's views about testimony were an attempt to answer Humean skepticism on this point.) Or perhaps I had better say that I wonder whether what Reid called the authority of testimony wasn't just a misnomer for what he was actually recognizing about the way testimony works. Perhaps, just perhaps, he not only noticed that 
With questions, of course, things are substantially different. There is no issue of believing what someone has asserted and no issue therefore of how epistemically reliable they are. If they are in a position of authority over one, that will affect whether or how one answers their question, but the issue will not specifically or usually be one of their having any epistemic authority. Whether one answers a question doesn't depend on whether the person asking it is some kind of epistemic authority, and in fact, and quite to the contrary, if they are authorities of that kind, then, unless one is in circumstances where one realizes that one's own knowledge is being legitimately tested, one may feel less need to answer their question: one may find it harder to believe that they really don't already know the answer to it. But authority of some other kind is not the most generally relevant feature of a situation in which one is asked a question. One answers the question because one recognizes that the person wants one to answer itand the switch from talk of intention here to talk of what someone wants has bearing on the main thesis I want to defend, the thesis that factors of empathy standardly play a substantial role in the working of speech acts.

When we think of nice people, we think of people who, within limits, are or want to be helpful to others. And one standard way of being helpful to others is to help those who want and say they want your help. But notice how odd it would be to put such a point in terms of intentions. If I recognize that someone intends for me to help them, that may raise my hackles, because it seems to leave the choice of whether to help less in my hands. And this isn't or isn't to the same extent the case if someone simply makes it known that they want my help. When someone asks me a question they standardly indicate that they want or need my help in the form of an answer to that question; and if I know the answer I can oblige them at little cost to myself. So anyone who is nice, who likes most others and

we often believe what others assert without having any argument from reliability to support that belief, but also, defender of common sense that he was, felt he had to offer an epistemic principle of the authority of testimony, based on theological assumptions, in order to explain how such beliefs could be justified in the absence of reliability arguments. But there is another possibility he may just have missed out on, a possibility very Humean in its way and thus, perhaps, something Reid might have been kept away from by its association (sic!) with Humean skepticism: the possibility that the so-called authority of testimony is not a separate epistemic principle of justification, but actually works in non-inferential justificatory terms via direct empathy with what others believe or know when they assert things to us. But since Hume was no sentimentalist about epistemology, there is no reason to think that what I am saying here about the empathy that Hume was the first person (at least in the West) to write about is something Hume himself would have agreed with. More on all this below. 
is well-intentioned toward them, will want to answer a question that they are in a position to easily answer. Believing what someone asserts seems to depend on thinking them reliable, but answering someone's question depends, typically, on how well-disposed one is toward them. This is an important difference, but I think it only makes a difference to how empathy enters into the functioning of assertion and asking a question as speech acts, not to whether it does. And since we have started with the speech act of asking a question, let me spell out the role of empathy there before discussing the substantially different role it plays in assertion. (Later I will say something about the role or roles it plays in other speech acts.)

Just above, I stressed the way in which a questioner indicates that they want or need the answer to a given question and the way in which an answerer may help or want to help the questioner by answering the question they have asked. (Of course, there are many different kinds of questions, and some of them, rhetorical questions, are asked in circumstances where it is clear that the questioner doesn't want the hearer to answer their question; and test questions are asked in circumstances where the questioner already knows the answer and is merely testing to see whether the hearer does. Still, the account I am about to give you is relevant to a wide range of questions in a wide variety of circumstances. Indeed, it is relevant to what it is natural to consider the most basic way in which questions are asked.) But notice that this way of putting things suggests that the asking and answering of questions raises moral issues. The hearer can be helpful to the questioner but may choose not to be, and, depending on their relation to the questioner and the past behavior of both the questioner and the hearer, it can be morally better or worse or, in some cases, outright wrong, if the hearer refuses to answer or gives a false or misleading answer. So the felicity and success of a speech act of questioning may depend on moral issues, on moral relationships, and John Searle's classical discussion of the speech act of questioning in his book Speech Acts doesn't mention this aspect of the matter. And neither, to the best of my knowledge, do other speech act theorists. (Notice that assertion doesn't raise this kind of moral issue because it doesn't call for the hearer to actively do anything for the speaker. $)^{8}$

But the moral dimension is important and it makes empathy relevant here too. Empathy with others makes us want to help them, and answering their questions is one example of the potential effects of empathy on

\footnotetext{
${ }^{8}$ Searle, Speech Acts: An Essay in the Philosophy of Language, Cambridge: Cambridge University Press, 1969, pp. 64ff.
} 
what we do and want to do on behalf of others. Most psychologists and philosophers who write about empathy assume there is a substantial connection between receptive/emotional empathy and motivation to help (I argued in fact for a very tight connection in Chap. 2), and if you will allow me to apply that assumption to the issue of asking questions, we can say that if a person who asks a question thinks it at all important to get an answer, the hearer who empathizes with them will be motivated to give them an answer. (This doesn't mean that they will answer or, in the case of pain, that an empathizer actually or automatically will help a person in pain. In both kinds of cases, it depends on the strength of the person's other motives at the time, but even when they don't help, the empathizer, in both kinds of cases, will still have some definite altruistic helping motivation vis-à-vis the person who needs or seems to need their help.)

I want to say, then, that the speech act of asking a question quite typically works via empathic processes. To be sure, if someone asks me a question, I might infer that they want me to give them an answer on an inductive or abductive basis. But I think it is more likely that I will simply register the fact that they attach some importance to getting an answer to that question: I will feel their felt need to have an answer more directly than via some sort of inference. And the questioning look on their face or their tone of voice can help make this happen: one can empathize with that look or face the way we empathize with a sad or fearful face or voice. When, in particular, one asks a question with a questioning look, one's face softens in an almost submissive manner, and that is presumably no accident. One is likely to get what one wants from someone if one doesn't demand it and if one shows them that one depends on them in the given circumstance. The submissive, questioning, softer look helps arouse the sympathy of the person asked for the person asking, makes it easier for them to empathically feel the need of the person asking the question, and the latter typically knows all this. They know that they have to soften their face (and their tone of voice) if they want to maximize the chances of having their question answered, and that is a significant and central part of how the speech act of questioning typically works or works well. (This is the kind of social knowledge Erving Goffman discusses in his magnificent Relations in Public. $)^{9}$ In other words, questioners know how to appeal to

\footnotetext{
${ }^{9}$ Relations in Public: Microstudies of the Public Order, NY: Basic Books, 1971. In discussing the ways we navigate our public interactions with others, Goffman mentions facial expressions and bodily gestures that we (unconsciously?) use to smooth or facilitate these interac-
} 
the empathy and sympathy of those they ask questions to and know that they need to do this, even if speech act theorists show no sign of recognizing this essential part of the typical questioning act or process. And the fact that everyone already knows all this in their practical life, even if not as theorists about that life, is partly shown by the fact that men are more reluctant to ask for directions than women. Men are typically less willing to be submissive to or show their dependency on others, and so their reluctance to ask strangers directions is some evidence for the empathyinvoking account of the speech act of questioning that I am sketching here. (One can't, in this connection, so readily point to the rising voice that occurs at the end of questions as a sign of submissiveness and softening because the rising voice occurs at the end of yes/no questions but not at the end of questions beginning with "who," "when," and the like.)

The practice (if that is the right word) of asking questions rests to a substantial extent on our capacity for empathy and on processes of empathy, and these facts need to be brought into the picture if we are to fully understand (central cases of) questioning as a speech act. And let me at this point make a comparison that may help strengthen the case for the involvement of empathy in speech acts like asking questions. Doing someone a favor is not usually compared to asking questions, but with respect to empathy there is an interesting similarity that it is worth our while to bring out. If someone does me a favor out of the goodness of their heart, I may infer that they have good intentions toward me, but I may also feel those intentions, empathically register their benign attitude toward me (the look on their face), and my thanking them may be a response to that benign attitude as manifested in the favor they do me. This response is not the response, of course, to a question, but in calling it a response, I think we implicitly recognize the similarity between someone's doing something for me and someone's asking me a question. In both cases, what the person does calls for a response and in both cases, very typically, that response is mediated by empathy with the psychological state of the other person: in the one case empathy with their benign motivation toward myself, in the other case empathy with their greater or lesser emotional investment in and motivation toward getting me to give them the answer they want

tions, for example, the fact that we smile when we accidentally trip over someone in order to indicate that our intentions are benign. But this is of a piece with the typically unself-conscious facial softening that helps facilitate the successful asking of questions. Goffman's ideas are relevant to speech act theory in a way that hasn't previously been recognized. 
or think they need. Moreover, this works not only with benign actions and motives but with unfriendly ones too. If someone deliberately hurts me, my empathic sense of their hostility, as manifested in what they do, can call for what we think of as a negative response. (More on this in later chapters.)

So there is, inherently, an emotional side to asking questions, and speech act theory should stop ignoring that fact and should incorporate that aspect of questioning into their overall account of that particular speech act. When we ask a question we may intend to get someone to answer our question by recognizing that intention. But we also convey our greater or lesser emotional investment in getting or having an answer and this is no accident. When we ask a question, we typically want the other person to see that we place a certain importance on their answering the question, and we may also be at some level aware that the way in which we ask the question may affect whether or how well it is answered. In asking the question, therefore, we make a kind of emotional appeal in the sense that we appeal to the person addressed via the emotion, not overwhelming emotion but definite emotion nonetheless, that we deliberately express and show the potential respondent in the very act of asking our question.

Now those who have applied speech act theory specifically to questions-e.g. John Searle in his book Speech Acts—don't fail to recognize that questions characteristically express the wish/desire of the questioner to receive a correct answer to that question from the hearer. The speech act theorist can say that if I deliberately ask a question, the hearer will recognize my intention to get him or her to give me an answer to the question and will also recognize that $\mathrm{I}$ intend him or her to do so as a result of recognizing my intention to get him or her to answer the question. But none of this can occur unless the questioner wants to have the question answered and expresses the desire to have an answer from the hearer when he or she asks the question. For the hearer's recognition of the questioner's intention is arguably based on or in the recognition that the questioner is expressing a desire for him or her to give an answer. So at the deepest level it is the expressive aspect of questions that constitutes the ultimate basis of and facilitator for the successful bringing off of a speech act like questioning. Those, like Searle, who see questions as expressive of desire don't see that this level of analysis or understanding is the most basic in the context of asking questions, that is, with respect to that particular kind of speech act. And, of course, and as I argued earlier, they also don't see the moral issue that the basic expression of desire raises. 
To that extent, then, we need an expressively based approach to speech acts like questioning rather than the familiar, standard intentionally based approach to them. The standard analysis of question asking in terms of intentions (and various more complex or accurate analyses that avoid known counterexamples to the original analysis) needs in some measure to be retained (intention is an awfully strong attitude), but I think it should be folded into an analysis that makes more of the expressive, empathic, and moral dimension of the speech act of asking a question. Because of what the speech act of asking a question typically is, it raises moral issues that speech act theory has simply ignored and that it needs to incorporate into the speech act approach to questions. More generally, too, I think speech act theory as a whole needs to take more account of the way empathy works in various expressive speech acts; and I think we can support this more general conclusion by considering the crucial role empathy plays in one of the most important or central kinds of speech act, assertions.

\section{4}

Assertions express desires and not just intentions. On the original unqualified speech act view, they express the intention that the hearer should believe what they have asserted on the basis of recognizing the speaker's intention to produce that result. ${ }^{10}$ As with questions, I don't want to deny that something like this is true in regard to assertions. ${ }^{11}$ But as with speech

${ }^{10}$ This takes Grice's original analysis of (non-naturally) meaning something and uses it to give an analogous account of assertion. I am indebted here to Peter Pagin, who makes just this sort of move in his account of Grice-type assertion in his article "Assertion" in the online Stanford Encyclopedia of Philosophy. He also mentions the counterexamples Searle offers to such an approach to assertion in his book Speech Acts and other problems that have arisen with Grice-type approaches to assertion and other speech acts. For very useful further discussion of the variety of counterexamples to Grice's account of meaning that started appearing in the years after Grice published his first article on the subject, see Wayne Davis's "Speaker Meaning" in Linguistics and Philosophy 15, 1992, pp. 223-253. Notice that even those (like Pagin) who recognize that assertion may well expresses the speaker's certitude and not just mere belief, don't make the further move of thinking the speaker may be attempting to get the hearer to have similar confidence and not just belief. This further possibility makes problems for standard speech act theoretical ways of dealing with assertion beyond the usual counterexamples-as the text above argues.

${ }^{11}$ In his article on "Speech Acts" in the online Stanford Encyclopedia of Philosophy, Mitchell Green suggests that loudness is not a relevant aspect of speech acts, but on the view being presented here, tone of voice and even loudness can be very relevant. The rising tone typical of certain questions tends to undercut the making of assertions, for example, causing the 
acts of asking questions, the asserting of something also expresses a desire for the hearer to believe something. Now I don't want to bring in morality at this point because I don't think it applies to assertion the way it applies to questions (and possibly commands and requests more generally). When we ask a question, we are requesting something of the hearer by way of an intentional action, and what someone does or doesn't do, whether in response to a question or more generally, can constitute a moral issue. But the asserter doesn't ask the listener to perform any intentional action; they just ask them to believe something, and what one does or does not believe may not raise moral issues as directly as issues about what one intentionally does or refrains from doing.

So I won't focus on moral issues with respect to assertion, and will focus more on epistemic questions. This will mean that the involvement of empathy in situations in which assertion occurs will more directly bear on epistemological issues than what we have just been saying about the speech act of asking a question. Of course, I haven't yet told you what I think the involvement of empathy in speech acts of assertion is, but it will help us to see how empathy is involved in assertion and to see how that bears on epistemological questions if we notice the weak way in which standard speech act theories speak of the intentions of those who make assertions. It is said that it is intended that the hearer believe what the speaker asserts, but in fact one can put things more strongly than this because assertion itself is more than the expression of a belief. As is becoming increasingly known in philosophy of language circles (though there are some dissenters), when you assert something you represent yourself as knowing and being sure of the truth of the proposition asserted, and both of these are stronger than belief. There are things we believe but aren't sure or certain about (for a time in the 1970s, I believed, was convinced, that Nixon had broken the law, but wasn't certain, wasn't sure that he had). And if we merely believe something and don't believe we know it, we don't (in good faith) assert it. We say something less bold like: I believe this or this, I believe, is true. When I take a plane to a very distant place I believe I will

speaker to seem less than confident about what they are saying and empathically conveying that lack of confidence to the hearer. And a certain level of loudness-but not shoutingmay actually serve to convey confidence (in both senses of "convey") and thereby make a speech act of assertion more effective in its purpose. (Women tend to speak more softly than men, and this raises some interesting moral and linguistic issues.) If empathy is relevant to speech act theory for all the other reasons I have mentioned, then tone of voice and actual loudness can certainly be relevant to (the felicity or success conditions of) speech acts. 
arrive safely, but don't believe I know that I will and am not, in fact, certain that I will. And that is why one doesn't just assert that one's plane will arrive safely at the distant destination. (There is also the point that when someone disputes an assertion I have made, they can idiomatically ask "How do you know that...?" in regard to what I have stated.)

So when someone asserts that $\mathrm{p}$, and not just that they believe that $\mathrm{p}$, do they merely intend the other person to believe the proposition that $p$ or do they intend that the other person share their great confidence in the truth of "p"? Perhaps the latter, and that fact, if it is one, can help us see how important empathy is as a factor in speech acts of assertion. (Incidentally, you can say something without asserting it, and I am not speaking of the speech act of saying.) Let's say someone believes that $\mathrm{p}$ and indicates, via assertion, that they believe that $\mathrm{p}$. Once the hearer recognizes that the speaker has a certain belief, they can base their own belief in the same thing on the previous reliability and honesty of the speaker (or on the prima facie authority of testimony à la Thomas Reid), and this seems unproblematic because it doesn't require the hearer to be certain that $p$. It is one thing to come to share someone's belief, but it seems different and more problematic if someone comes to share an asserter's certainty that $\mathrm{p}$ on the mere basis of the asserter's having, in the speech act of assertion, represented himself or herself as certain that $\mathrm{p}$. In terms of inductive or abductive arguments, one can see someone's being willing, on the basis of a speaker's previous reliability, to believe what they believe and want you to believe, but unwilling to be confident or certain about $\mathrm{p}$ the way the speaker is. (As I mentioned in Chap. 2, my dictionary says confidence is a state of strong belief.)

When a speaker makes an assertion, they represent themselves as knowing and being certain and confident, and they also intend or wish for the hearer to accompany them beyond mere belief. But if the hearer's going with them that far depends on their having a good argument from reliability for being certain of what the reliable speaker is saying, such an argument, as we have said, isn't likely to be forthcoming. So how can the speaker expect the hearer to have the degree of confidence that he, the speaker, wants and intends for the hearer to have? How can this be realistic? How can a speech act that intends to produce more than mere belief really be appropriate and felicitous in the way we think assertion typically or often is?

The answer, I think, lies in the operation of empathy and in ordinary people who make assertions being implicitly aware of how empathy can work in the context of assertion. If empathy is at work when assertions are 
(felicitously and successfully) made, then the hearer may be able to take in the certainty of the speaker in the unconscious way in which empathy works in other cases. The father who is infected empathically by his daughter's enthusiasm for stamp collecting doesn't know that that is happening to him (though he may figure out later that it has happened to him), and when an asserter makes their assertion, the hearer may take in the confidence and certitude that lies behind the assertion and become as confident or almost as confident as the asserter. They may thus arrive at something more than, stronger than, (mere) belief even if some kind of reliability argument would only justify belief. And this fact, this strength beyond what an argument from reliability could justify, is not necessarily an epistemically unfortunate development. On the contrary, if the speaker is appropriately confident about what they assert or claim, if they personally have overwhelming evidence for it, then the empathic taking in of a similar state of confidence will be epistemically useful to the hearer. When something hangs on a given question, it can be better to know and be confident of the answer to that question, than to merely believe in a given answer to that question. So if it is an epistemic advantage to the speaker, the asserter, to be confident about and not merely to believe a given proposition, then it can also be an advantage to the hearer to empathically take in that confidence or certitude. (Notice too that when we assert a fact to someone, we assure them of its truth, and the obvious conceptual connection between assuring and being sure indicates that our ordinary thinking about assertions implicitly assumes that assertions can make people sure. How else can this occur except via empathy?)

All this helps make sense of our common practice of assertion in a way that standard speech act theory does not. The latter allows us to understand how belief can result from assertions and how the asserter can believe that it will. But it doesn't explain how certitude or genuine confidence can arise from assertions and how a speaker can be relying on that fact in the most common cases of making assertions. An account of the speech act of assertion that relies on empathy can, however, explain these facts. It can hold not only that people can empathically take in the epistemic confidence of those whose assertions they hear (or read), but also that those who make assertions are more or less implicitly aware of the way the sheer force of asserting (as opposed to qualifying things with "I believe") can get to the hearer, can influence the hearer. And in standard cases of assertion (I am not talking about cases where one asserts something knowing full well that the hearer will not grant what one is saying, cases where one just 
wants to be heard and wants the truth to be strongly expressed) the speaker is relying on the fact that assertion has a certain force that as a force will influence the hearer. That force is the force of strong feeling, and the asserter typically feels or understands that he can or may be able to get the hearer to believe as strongly as he does if he makes a peremptory assertion of a certain claim. A loud (but not too loud, not shouting, which can actually indicate a lack of confidence and so of sincerity) voice can also be used by the speaker for that purpose, and the speaker may actually come spatially closer to the hearer in making the assertion, based on an implicit knowledge that feeling and attitude are more strongly and surely conveyed over a short distance than over a great distance. ${ }^{12}$ (As Hume told us, empathy works better when distances are small.) But none of this comes out under the standard interpretation of the nature of the speech act of asserting, and that gives us a reason to bring empathy into a fuller, more accurate account of that speech act.

Now one might argue back here that what I have said doesn't account for the hearer of an assertion's being justified in the kind of confidence that is often empathically conveyed via assertion. Perhaps asserters rely on the irrationality of those they make assertions to, when they expect their confidence to pass along to those they make their assertions to. But I don't think they can plausibly be thought to be relying on any such assumption. After all, today's asserter is tomorrow or yesterday's hearer of an assertion, and those who make assertions and hope for their confidence

\footnotetext{
${ }^{12}$ One can take in one's parents' attitude to bears or to Aunt Tilly without their ever asserting or telling one that bears are dangerous or Aunt Tilly trustworthy: one may (and children are good at this) simply feel, empathically feel, what one's parents think or feel about bears and Aunt Tilly. But such cases are actually closer to cases of assertion than one might think. Confidence may be empathically conveyed or infused via an assertion, and assertion as a speech act is (among other things) fundamentally characterizable as a conventional way to get people to take in our confidence on some subject matter. So assertion facilitates and makes socially available what can happen without express speech acts in the family: the empathic transmission of belief and confidence. And no argument from reliability need operate in the mind of someone who takes in beliefs in this way. The child doesn't need it, and neither, in parallel, does the person who hears an assertion. Since the usual speech act theories of what happens with assertions do at least implicitly rely on the idea that the hearer of an assertion needs to make some sort of argument in their own mind in order for the speech act of assertion and the speaker intentions that lie behind it to come off successfully, this shows you how far speech act theory has been from actually capturing what is involved in assertion as a speech act, from capturing what happens when assertion works the way the asserter typically assumes or hopes it will work.
} 
to empathically convey itself to a hearer are not so obtuse and unaware as not to realize that they too are influenced into confidence by assertions made by others. Are we to suppose that the ordinary asserter really thinks that $\mathrm{s} /$ he and everyone else is being cognitive irrational during the standard and familiar processes of conveying confidence, even great confidence, via assertion? On commonsense grounds, rather, I think we should consider the strong possibility that what is conveyed directly via empathy can as such be justified. The child's belief that bears are dangerous is conveyed to them via empathy and without any particular argument having to occur to the child, and non-inferential or direct justification arguably also occurs with respect to our memory and perceptual beliefs. In other words, I want to argue (and have done this at length in Chap. 4 of the book referred to in footnote 1 Chap. 2) that we don't need to base (all or most) cognitive or epistemic justification on inferences and that the epistemic receptivity exemplified in the confidence we show in what our senses, our memory, or our empathy tells is an epistemic virtue that grounds the epistemic justifications we have in these areas. (More needs to be said, but, as I just indicated, that more is said elsewhere.)

However, we shouldn't overestimate the force or role of empathy here. Assertions typically or normally work in the way I have been describing, but if someone has strong evidence, perhaps of a perceptual nature, against what someone is asserting, a countervailing epistemic and psychological force will operate to weaken or blunt the force of the empathic transmission of what the asserter is asserting and believes herself to know. Similarly, in the kind of case discussed earlier, if one empathically picks up on a child's fear of worms but has independent reason to doubt the dangerousness of worms, that may undercut the acquisition of any knowledge of or reasonable belief about what the world is like on the basis of the transmission of the child's fear of worms. What I have described as the epistemic and linguistic role of empathy operates only when there are no strong countervailing epistemic factors (again, this holds for perceptual beliefs as well). But speech act theory has left this role entirely out of the picture. Now to a bit of history.

When Thomas Reid spoke of the authority of testimony, he wasn't talking about sympathy/empathy in Hume's sense. However, what we have been saying here represents a kind of vindication of Reid's views, though in a more sentimentalist direction than he presumably would have welcomed (but who can be sure?). Reid said that what people attest to or assert has authority with the hearer, that the hearer has reason to believe it 
(or be confident) independently of having any inductive argument for the reliability of the given speaker or of speakers generally. But what we have said about empathy can fit (i.e., fill) this bill. Authority in its paradigmatic examples has both de facto and de jure force or power, and our account of how empathy works and works in the context of assertions allows it to have both those features. Empathy has de facto force in this context because as a causal matter we tend, through empathic osmosis, to take in the confidence of someone who assertorically tells us something. And it has de jure force too if we allow that (empathic) receptivity can epistemically justify. We said earlier in this chapter that a child can gain information about the world through taking in their parents' or a given parent's attitude (not necessarily asserted) toward certain things, people, or situations in the world, and what applies to parents can just as easily apply to what happens in the context of assertions. The same receptivity that makes us take in, without doubt or hesitation, what our parents think about bears or Aunt Tilly can make a listener take in what a speaker asserts in the same unhesitating and confident way. And don't say the cases are different because parents are, after all, parents. My argument earlier in no way relied on that fact, but just relied on the justificatory force of receptivity through empathy, but in that case when someone asserts something to our face, their empathic influence may be very strong too. Hume tells us that "sympathy" works via the principles of association and that proximity and similarity increase its force. So there is no reason why assertion shouldn't have a similar influence on a stranger when the asserter is right near the stranger. And even if what one reads in a book may be less causally effective in this spatial way, books allow their own form of causal immediacy: when one reads one is in a kind of causal isolation booth with the author, and that can allow the force of an author's opinions to in some sense directly influence the reader. (This intimacy and influence are one reason why we like to read books.) In keeping with this, we can say, too, that the oral or written asserter knows all of this implicitly, and makes use, so to speak, of the realities of receptivity to empathic transmission when they make an assertion and expect to influence the hearer to share their strong opinion.

Now Hume thought we tend to be influenced by the opinions and attitudes of anyone near us (see the famous section "Of the love of fame" in the Treatise of Hume Nature). But Hume was also no sentimentalist about cognition or epistemic rationality. And once one allows that the mechanisms that Hume viewed independently of issues of justification can do justificatory work through the epistemic virtue of receptivity (a virtue 
Hume never for a moment recognized), we can see that the speech act of assertion can justify believers in having confidence: not always but certainly often. This then comes close to what Thomas Reid said about authority. Yes, assertions and testimony have authority, as Reid held. But that authority is a function of receptivity and empathy in a way Reid never suggested but we are suggesting here-and it in no way depends, as Reid held, on God's instilling veracity and/or credulity in us humans. Reid may have been dimly aware of empathy, and his talk about the direct noninferential way we believe what people tell us may derive (further) theoretical justification from what we have been saying about empathy and receptivity in these pages. (We might even say that the authority of testimony he spoke of turns out to be nothing other than empathy and its receptivity functioning in the context of testimony/assertion.)

Thus the empathy-emphasizing epistemological approach taken here comes closer to Reid's somewhat rationalistic views than to the epistemological views of Hume the empathy-empathizing moral sentimentalist. Which is odd, to be sure, but I think undeniable. Hume believed in empathic/sympathetic influence, but he didn't think such influence justified us in believing what people tell us and held, rather, that we need evidence of a speaker's reliability before we have reason to believe her or him. Hume was very far, in other words, from the kind of epistemological sentimentalism I am advocating here and that, as I have argued, Reid adumbrates in what he says about the (non-inferential) authority of testimony. Just as a final point, I should also mention that Reid underscores the similarity between perceptual belief and belief in testimony, in assertions. He holds that both operate and justify without arguments, and I am tempted to say-let me just say-that what we have done here may help vindicate this comparison. Reid may not have spoken of receptivity, but if the view of the present book is on the right track, then receptivity operates both in and for perception and in and for confident belief in what is asserted to one (also in and for memory), and this, yet again, gives further, non-theological support to the comparison between perception and belief in testimony that Reid drew in his Inquiry.

The present chapter has sought to give support both to what Hutcheson said about the moral sense and to what Reid said about the authority of testimony, and so it argues in favor of a somewhat anti-Humean view of these matters; for Hume didn't believe in the authority of testimony and didn't believe that there was anything that could accurately be called a moral sense. So, again ironically, it is by relying on the notion of empathic 
contagion that Hume was the first person to describe in any detail that we end up, in the present book, with such anti-Humean epistemological views.

And now I would like to do a little more history in order to place what I have just been saying in a somewhat larger philosophical context. The idea that certain speech acts of assertion can and do rely on processes of empathic transmission is not entirely original to me. It can be found in the work of Charles Stevenson and most specifically in his "The Emotive Meaning of Moral Judgments," but in application only to value judgments. ${ }^{13}$ Stevenson says that the feelings of someone who makes an evaluative claim can spread by contagion to the person who hears the claim being made, and though he doesn't use the term "empathy" he is clearly referring to what Hume called sympathy (sometimes using the term "contagion") and what we nowadays call empathy. Of course, given the time at which he was writing, Stevenson doesn't talk of speech acts nor home in on assertion as a special kind of speech act, but the cases he describes are in fact cases where the speech act of assertion is occurring, where the empathic transmission of feeling occurs or is likely to occur, and where the utterer implicitly knows and makes use of the fact that such transmission can take place.

So Stevenson is in effect describing a particular instance of what I am saying more generally about the making of assertions. His view was applied only to value judgments and the feelings they express, but I am saying that every assertion expresses feeling or feelings that can be transmitted empathically to a hearer and that the speaker wishes to be transmitted in that way. ${ }^{14}$ In fact, more strongly, an intelligent asserter relies on the fact of emotional contagion as a means of achieving the goal of their assertion, a certain epistemic state of the hearer, and this fact is essential to the way the speech act of assertion works (among humans). (Everyone knows practically about empathic transmission even if they don't have the technical vocabulary to describe it. Someone two hundred years ago could have said that he was infected by his daughter's enthusiasm for coin collecting, even if he didn't explicitly know that there was such a thing as empathy and even though the term "empathy" hadn't yet been invented.) So it

\footnotetext{
13 “The Emotive Meaning of Moral Judgments," Mind 46, 1937, pp. 14-31.

${ }^{14}$ Footnote 6 above makes the further point that Stevenson exaggerates the empathyarousing emotive force of value judgments by not recognizing that that force is (at least in many cases and sometimes even in advance) cancelable. But the important point, in any event, is that all assertions express an emotion of confidence that can be empathized with.
} 
would seem that empathy and knowledge of empathy are essential to assertion as a speech act and need to be brought into speech act theory in a substantial way.

At this point, however, we also need to recognize the twofold character of the feelings that an act of assertion empathically conveys. An assertion empathically conveys the (feeling of) confidence the speaker has in some proposition, and as we have seen, this can cause the hearer to be similarly confident. But assertion can also convey the speaker's desire or eagerness that the listener share his or her confidence in the proposition asserted. I am not sure what epistemic role this second kind of empathic transmission can play, but it perhaps plays a (larger) human role, inasmuch as the eagerness to share a view may represent a kind of basic or partial desire for some kind of epistemic community or solidarity with the hearer. This may indeed bring the moral into our account of assertion, but I am not really clear about this, not nearly as clear as I am that the asking of a question brings moral issues in its train.

\section{5}

I said earlier that I would say something about other speech acts in the light of what I was going to say about the role of empathy in asserting and asking questions. But I hope the reader won't mind if I am fairly brief about this. Searle takes up the speech acts of warning and thanking in his book Speech Acts, and these seem far enough from assertion and questioning to allow us to see how empathy might be relevant to all forms of speech acts. Allow us to see, that is, if thanking and warning as speech acts can be shown to rely on empathy. Let's begin with thanking.

First, why do we thank someone? Isn't it because the person has done something for us for which it is appropriate to show gratitude? Now in the most standard cases gratitude is a state arrived at empathically. We often feeling the good will or generosity behind an act for which we owe thanks, and gratitude typically reflects that good will or generosity. We empathize with the generosity, we feel the good will, and such feeling powers our own feelings of gratitude. Since thanking is standardly an expression of gratitude and is less appropriate or felicitous if we don't feel gratitude, we can see that empathy necessarily lies in the background of the speech act of thanking someone-even if this point is missed by Searle and others who have spoken about this speech act. But one can say more. Thanking expresses gratitude on the part of the thanker to the person who has given 
one something or done something for one, and this is central to the speech act of thanking. So thanking represents good will reciprocated, good will as a response to good will, and what, then, is likely to happen as a result of that second instance of good will? Well, the original giver is going to recognize the good will they have elicited from the person they have done something for, is going to feel that second-occurring good will, and the results is likely to be reinforced good will, more good will, on the part of the original giver. And how is that further or reinforced good will likely to be expressed? By a "you're welcome!". But Searle and others seem to ignore this further, concluding dimension of the speech act of thanking. When we thank someone sincerely, we expect them to reciprocate by saying "you're welcome!" and that is part of the human meaning of the speech act of thanking. (I will have more to say about gratitude and reciprocity in Chap. 8.) Here there is obviously a moral dimension because if the other can but doesn't say that the person benefited is welcome, they are less gracious, less nice to the benefited person, than they should be. It's as if they weren't fully following through on their original good intentions or motives, and that is a moral deficiency. (If the benefactor didn't originally have good intentions toward the beneficiary of their action, the beneficiary's "thank you" may somehow [I think] be felicitous, but any "you're welcome" in the part of the benefactor will be hollow and misleading, and there will then be something infelicitous about the whole sequence. But the infelicity will be different from that which occurs when the originally beneficent benefactor insouciantly fails to say "you're welcome.") Thus thanking as a speech act standardly comes about as a result of an act of someone else's good will and standardly causes a further act of good willing (on the part of that someone else) in the form of a "you're welcome". (This is obviously partly conventional; in some contexts a bow acknowledging thanks will do just as well.)

Thus if we regard thanking in its full timeline as a speech act, we need to bring in empathy in order to explain what standardly or typically happens (and what is presupposed by and/or necessary to felicity or success) when we engage in that speech act. And the same goes, I think, for warning. To warn someone is standardly to indicate that that the person you are warning is in some danger and standardly also indicates that one cares about what happens to the person one is warning. This can make both a moral and an epistemic difference. If one warns someone, the fear on behalf of the person that one typically expresses can convey itself to the person who is warned in much the same way that the fear of bears can be 
conveyed from parents to a child who empathizes with their fear. In both cases there is epistemic advantage to be had out of the direct transmission of the fear. And warning makes a moral difference because it standardly conveys, empathically conveys, a sense of solidarity, on the part of the warner, with the person being warned, a kind of shared interest in the warned person's not being harmed. And of course, too, if the person warned takes heed of the warning, they will typically be grateful to the person who warns them. Gratitude is expectable after the speech act of warning, and that fact also essentially characterizes what it is for someone to warn another person. So just as thanking as a total speech act only makes sense when one brings in the front-end condition of a favor done and the back-end condition of the thanked person's saying "you're welcome," warning only makes sense as a total speech act if one includes the front-end condition of concern or fear for another person and the backend condition of gratitude and at least minimal solidarity (or community). Finally, and perhaps most obviously, warning standardly involves assertion. When one warns someone, one is likely to empathically convey one's fear for the other person but also (and as involved with or in the fear) one's confidence that there is something to be fearful of. Thus all the features of empathy and emotion that attach to assertion also attach to typical warnings. (Notice that the person who warns conveys the fact that they epistemically favor a certain hypothesis about the future at the same time that they convey their unhappiness with the possible or likely future that that hypothesis describes.)

In the light of all that I have been saying, I think that we or someone needs to go through all of speech act theory revising it in a direction that takes into account both empathy and the front-end and back-end conditions that at least some speech acts involve. ${ }^{15}$ As we have said and seen, this

${ }^{15}$ Above I mentioned thanking and warning as two prime examples of temporally extended speech acts with front and back ends that speech act theory needs to take more account of. Let me mention another example, one that, like the other two, involves gratitude, but whose full felicity doesn't involve any direct expression of thanks. If a student asks to work with a given professor and the professor tells them "Yes, I will accept you as my student," the student may tell the professor that they feel honored to have been accepted by someone so distinguished, and so on. But this rather oblique expression of gratitude can be met, at the professor's end, by the latter saying: well, I feel honored by the fact that you feel honored by my accepting you as my student. Such a (clever) response seems quite natural, and in its absence one might think the professor was being less gracious than they could or should be. If the professor does express a sense of being honored by what the student has said, this is not really a "you're welcome." But it completes that communicative exchange in a rather 
requires us to recognize that empathy plays a number of epistemic and moral roles that have somehow been neglected in moral philosophy, in epistemology, and in speech act theory. ${ }^{16}$ When we ascribe empathy we are making a psychological claim or attribution, but such attributions are relevant to philosophy in many areas and in ways that have not previously been suspected.

nice way, and that is why I think it has much in common with the examples of warning and of thanking. The temporally extended speech act here is the act of vocally accepting someone as one's student, and I think we can see that that act involves both back end and front end (the student has to have applied to the professor in some verbal way) felicity conditions.

${ }^{16}$ The earliest developments in speech act theory occurred during a period when empathy was little known about in the academy, so there is some excuse for practitioners like J. L. Austin, H. P. Grice, and perhaps even John Searle not to have noticed the considerable role empathy plays in successful speech acts. But there is no such excuse today, and it is high time for speech act theorists to take empathy into account. 
Open Access This chapter is licensed under the terms of the Creative Commons Attribution 4.0 International License (http://creativecommons.org/licenses/ by $/ 4.0 /$ ), which permits use, sharing, adaptation, distribution and reproduction in any medium or format, as long as you give appropriate credit to the original author(s) and the source, provide a link to the Creative Commons licence and indicate if changes were made.

The images or other third party material in this chapter are included in the chapter's Creative Commons licence, unless indicated otherwise in a credit line to the material. If material is not included in the chapter's Creative Commons licence and your intended use is not permitted by statutory regulation or exceeds the permitted use, you will need to obtain permission directly from the copyright holder.

(c) (1) 